\title{
Visual and Interactive Tool for Product Development Process Enhancement: Towards Intuitive Support of Co-located Project Review
}

\author{
Samira Sadeghi, Cédric Masclet, and Frédéric Noël \\ G-SCOP, Laboratory for Sciences of Design, Optimization and Production, Grenoble, France \\ samira.sadeghi@g-scop.grenoble-inp.fr, cedric.masclet@g-scop.eu, \\ frederic.noel@g-scop.inpg. fr
}

\begin{abstract}
Product life management refers to every method or tools which participate to the collaboration of actors involved along the product life. The main topic concerns the organization of this cycle by mastering the evolution between its various phases. Collaboration is a main bottleneck since every phase will involve different experts. The main issue in collaboration is to ensure a good understanding of requirements and constraints of collaborators and to manage conflicts between different experts. Negotiations are expected to solve potential conflicts. This is usually done in project review where the experts must converge towards a common solution. In this paper we investigate the efficiency of a tool formalizing and structuring the project review activity. This tool takes advantage of emerging technologies, here a multi-touch table. We illustrate the discussion with a use case concerning the development of personal computer housing.
\end{abstract}

Keywords: Collaborative work, Project review, Conflict solving, Intuitive interaction.

\section{$1 \quad$ Introduction}

Product development process is structured around well-defined phases; each phase ends with a decision-making meeting where management decides about the future of the project [1]. One of fundamental elements of product development is the coordination of this process, which ensures the information flow, collaboration, and cooperation among multiple parties, involved in the product development activities.

In most cases, experts (design engineers and other stakeholders) work separately, changing representations of alternative versions of the product. Each of them is an expert in his respective field of knowledge, and has his own valuable contribution to the overall development cycle.

During product development process different expert cooperate and collaborate in synchronous and asynchronous mode. In addition to all the challenges of group working, experts have different values and criteria, backgrounds, and languages that are more or less accessible through the traditional digital mockup (DMU). We assume that efficiency of collaboration between experts will be based on the improvement of interactions between all experts as soon as possible [2]. 
Negotiation is engaged as a potential mean for solving conflicts, thus converging to a new common view of the project. This interaction is usually accomplished during project review which becomes the decisional point in product development process. During project review experts must identify potential conflicts issued from asynchronous activities, and then they must try to solve them by finding the best compromise between different objectives related to different domains. It requires to evaluate, compare and select alternative solutions and to optimize from a global perspective. However, these project reviews are the less formalized activities within design tasks. Usually experts expect to base their discussion on a common representation. Contribution of different disciplinary in evaluating different alternatives is fundamental to enhance the level of evaluation by considering implicit knowledge and explicit knowledge of different disciplinary.

We seek to use new visualization and interaction technology to support these phases of product development (i.e. project review). Complex activities such as conflict resolution are often facilitated by face-to-face negotiation meetings. In this we investigate how to improve co-located project review. We expect to make interaction more intuitive thanks to the support of a multi-touch table. This work is a complementary effort for researches delivering shared product models for PLM. Whatever this shared models are efficient they are still hard to manipulate. A step towards new user interfaces in a CSCW perspective (Computer-Supported Cooperative Work) becomes obvious for PLM issues.

Section 2 of this paper models the product development process, concurrent engineering strategies, and conflict detection and resolution. We focus on multiple view effects. To illustrate our discussion we defined a use case/scenario in Section 3. In section 4 we analyse how project review phases in product development process are organized. Then, in Section 5 we proposed a visual-collaborative-interactive tool that is designed to support project review phases in product development process.

\section{Product Development Process}

The design process is essentially a cooperative process in which multiple actors, views, practices, methods and design tools converge towards a common goal: a design solution which fit the specifications and meets the constraints of each business. To achieve this goal, it becomes increasingly necessary to create common design platform to promote links between different fields of application and the interface between different technologies and practices, and thus favor cooperation. We need to formalize a model for cooperation. We assume that, cooperative activity is an iterative process with a sequence of asynchronous activities [3] and common works to synchronize models and goals of every actor (Fig. 1). In this process, experts models (Model 1, 2 and 3) are updated on an asynchronous mode to create new versions Model 1', 2' and 3', etc. The first act of cooperation is then to present and compare these models to identify the potential differences, lacks or conflicts. Every expert usually discusses and proposes solutions that must be evaluated and negotiated (it cannot be automated) to converge on a comment agreement: a pragmatic decision. Then the decision must be applied in every expert perspective and a new loop of this process may be executed. 


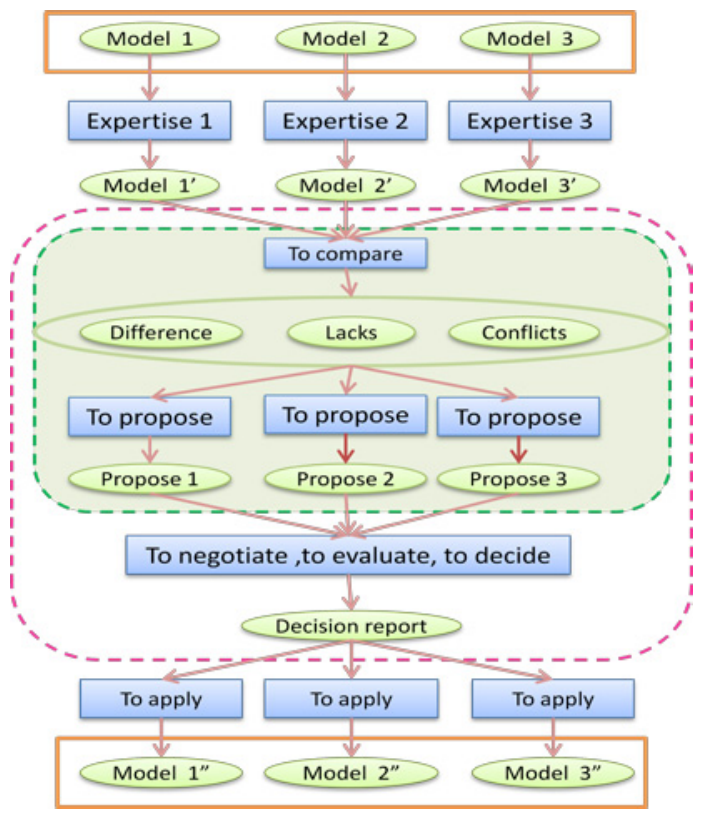

Fig. 1. A model for cooperative design (re drawn from [3])

\subsection{Concurrent Engineering in Product Development Process}

The comparison phase of the previous model expects a common space to share information. Currently the industrial solution for collaboration between experts in design is performed using PDM (Product Data Management). It enables experts to share files from their familiar softwares (usually saved in native formats). PDM infrastructure can be extended to a larger number of stakeholders to accelerate product development while preserving accuracy and confidentiality of information. PDM systems are based on a high-level approach by providing structured information for the design. However, the design details are not visible thus reducing their effectiveness in the analysis of the complete design of a product or during the implementation of gradual changes in design elements. PDM systems do not support situations of cooperation where the expert has to share in detail the parameters of the product.

The difficulty is then to create cooperation ties between the different models often heterogeneous (referring to various ontology, ontology turn out never to be unique), to a fine level of granularity (within files). In order to enable product development, engineers take part in an iterative process of exchanging proposals, rejections, supporting arguments and compromise until a consensus is reached. Expert representation becomes an excellent way to interact not only with players in the same field, but also with the various organizations of the company. The creation of interactions between designers requires the presence of one or more common shared objects. 


\subsection{Conflict Detection and Resolution during Product Development Process}

For the purpose of this paper, we define a conflict as a disagreement between two experts in the design whose views or objectives appear contradictory. In most cases, designers work independently, modifying alternative versions. All argues that occur should require a negotiation phase. The resulting decisions must be propagated to change the different model of every designer. This is usually done during a synchronization phase of the different model versions. Thus, modification of an entity within a specific view can be the consequence of a conflict with entities from other views. Interoperability methods are not mature enough to preserve the coherency of the views. Therefore, identification of a change impact must remain a human leaded activity. This human process does not complete a tracking of all changes to a shared model. Therefore, an effective approach to detect changes in common model is needed to significantly improve the synchronization process. Edwards [4] proposed a flexible conflict detection and management method. Matta [5] defines a library of associations between concurrent engineering sub-tasks and conflict management methods to guide an agent to determine appropriate methods to manage conflicts. Jung et. al. [6] proposed a method for conflict resolution by coordination and argumentation agents. Barber et. al. [7, 8] proposed to use multi-agent systems for conflict detection and resolution. $[9,10,11]$ proposed to use role management and role-based regulations to simplify the task of conflict resolution. Many possible conflicts can be avoided with the role assignment, management and regulations.

However we must insist: conflicts will not be automatically detected and resolved. Human experts are required to be able to generate new solutions. In other words finding innovative solution requires a good understanding of requirements of each expertise and problem context and better collaboration between experts. Designer must negotiate to merge their changes to a new version of the object. In our point of view, this strongly rely on the ability to provide environment that support external representations which will act as intermediary objects. Supporting the negotiation activities is an important issue for Product Lifecycle Management.

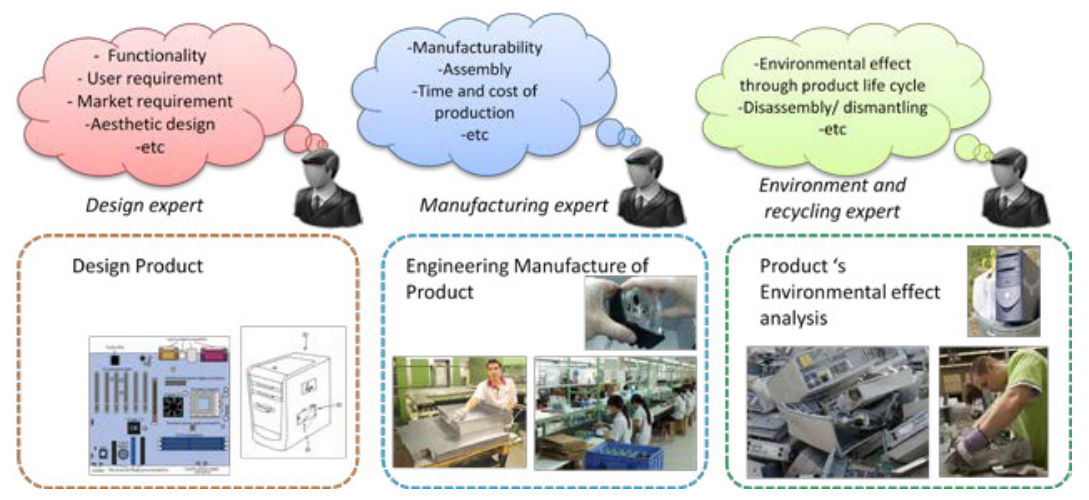

Fig. 2. Different objectives and point of view between different experts involved in the Product Life Management of a personal computer housing 


\subsection{Different Points of View in Product Development Process}

Product development is a collaborative and distributed activity. Each expert from one or more fields has his/her own technical point of view to design and build a product. He uses his specific ontology to represent his product view. Each expert participates to the design of the product by building models compatible with a particular view. Fig. 2 shows an example of the product "personal computer housing" according to multiple views. It shows difference between objectives of different experts. According to [12], a business view is generated by applying the knowledge and taking into account the rules of a particular job. Indeed, the vision of a design object is quite subjective and is dependent on the prejudices of the culture of each one and probably several other hard to identify factors. Having a common representation (geometrical model for instance) doesn't imply that actors will associate the same meanings to this representation. Designers, because of their expert status, are able to engender a lot more of knowledge than the representation is conveying. A view can be of two types:

- Common to several players from the same expertise or different expertise;

- $\quad$ Specific to a particular actor / expertise.

\section{A Use Case Definition}

To illustrate our discussion, we consider the development process of the housing of a computer. Figure 3 provides an overview of the overall process and takes into account the constraints of all phases. This model is based on the assumption of a parallel design activities flows. Three dominant perspectives in product life cycle are design, manufacturing and environmental effect analysis. The design team operates within constrained ranges specified by the manufacturing and environmental experts.

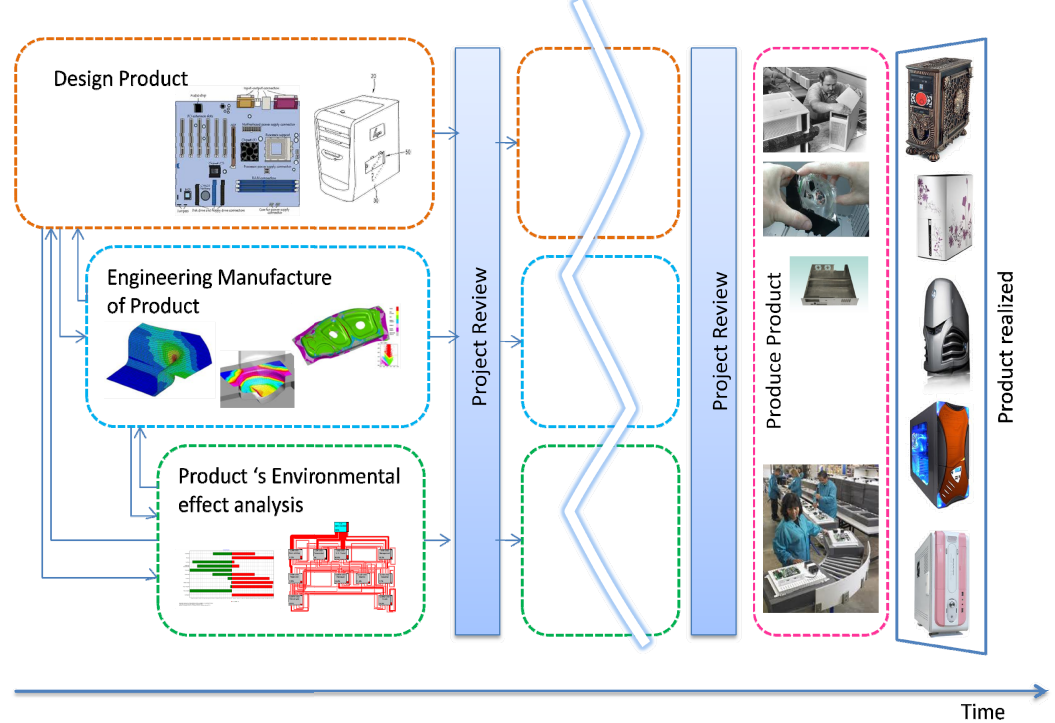

Fig. 3. Process of product (personal computer housing) development 
Prescriptive communication between phases, in the case of a concurrent design, corresponds to the project reviews. Representation of the design process, according to the concurrent model, should reduce the development cycle of the product.

We already discussed the importance of the project review as the principal way to ensure the convergence towards a common product definition. The diversity of environments used on one hand and the problems of transfer and exchange of knowledge and data on the other hand, requires the integration of different phases. Each expert should consider the outcomes of others, through efficient collaboration, exchange control to maintain consistency between phases. A designer should be able to cooperate and integrate his knowledge with the knowledge of the group, and thus take into account the constraints from others.

The proposed use case concerns the design of personal computer housing. A CAD expert will be in charge of dimensioning the product and usually will provide a parameterized geometric model. He will be also concerned by some standardization rules to integrate other components within the housing. A simulation expert could check (for instance by using Finite Element Methods) some thermal issues linked to the air flow or study of the structure by analyzing resonant frequencies. The manufacturing expert will be concerned by the sheet-metal manufacturing process. How to cut and bend the sheets: time of production, quantity of material will be his own focus points. The recycling expert will focus on disassembly techniques, separation of components (plastics, sheet metal, etc) and the selection of materials.

\section{Project Review Phases in Product Development Process}

We can observe how cooperation is supported in usual projects. We assume that a few situations are characteristics of most cooperation activities. In the upper side of Table 1 we summarize the situations with common settings of co-located meeting. Each way has specific characteristics, advantage and disadvantages. Both horizontal and vertical surfaces are studied knowing that the group performs differently according to the nature of collaborative activity [13]. A summary is proposed in Table 1 . The analysis of the different configurations helps us to have a better specification for a tool to support different aspects of meeting for project review. 
Table 1. Characteristics of common ways of meeting

\begin{tabular}{|c|c|c|c|c|c|}
\hline \multirow{3}{*}{$\begin{array}{l}\text { Way of holding } \\
\text { meeting for } \\
\text { project review }\end{array}$} & \multicolumn{4}{|c|}{ Most common configurations for co-located meeting } & \multirow[b]{2}{*}{$\begin{array}{l}\text { Our proposed } \\
\text { Hardware and } \\
\text { Software(MT-PR) }\end{array}$} \\
\hline & $\begin{array}{l}\text { 1/ } \\
\text { Project review } \\
\text { around the table } \\
\text { with physical } \\
\text { material (printed } \\
\text { documents) on } \\
\text { the table for } \\
\text { meeting }\end{array}$ & $\begin{array}{l}\text { 2/ } \\
\text { Discussion } \\
\text { based project } \\
\text { review }\end{array}$ & $\begin{array}{l}3 / \\
\text { Project review } \\
\text { around the } \\
\text { computer with } \\
\text { digital material }\end{array}$ & $\begin{array}{l}\text { 4/ } \\
\text { Presentation } \\
\text { based project } \\
\text { review }\end{array}$ & \\
\hline & & & & & \\
\hline $\begin{array}{l}\text { Physical resource in } \\
\text { room }\end{array}$ & Table and chairs & $\begin{array}{l}\text { Table and } \\
\text { chairs/ } \\
\text { whiteboard }\end{array}$ & $\begin{array}{c}\text { Computer } \\
\text { /keyboard/mouse/t } \\
\text { able and chairs }\end{array}$ & $\begin{array}{l}\text { Video projector/ } \\
\text { Computer/table } \\
\text { and chairs }\end{array}$ & $\begin{array}{c}\text { Multi-touch table } \\
\text { /chairs }\end{array}$ \\
\hline Shared object & $\begin{array}{l}\text { Printed } \\
\text { documents/ } \\
\text { physical } \\
\text { mockups }\end{array}$ & $\begin{array}{c}\text { Drawing } \\
\text { shapes and text } \\
\text { on the board }\end{array}$ & $\begin{array}{l}\text { Digital objects } \\
\text { and documents } \\
\text { Digital mockups }\end{array}$ & $\begin{array}{l}\text { Digital objects } \\
\text { and documents } \\
\text { and Digital } \\
\text { mockups }\end{array}$ & $\begin{array}{l}\text { Digital objects and } \\
\text { documents and } \\
\text { Digital mockups }\end{array}$ \\
\hline $\begin{array}{l}\text { Documentation of } \\
\text { discussion }\end{array}$ & $\begin{array}{c}\text { each expert can } \\
\text { have his/her } \\
\text { own notebook } \\
\text { for documenting } \\
\text { discussion }\end{array}$ & $\begin{array}{l}\text { each expert } \\
\text { can have } \\
\text { his/her own } \\
\text { notebook for } \\
\text { documenting } \\
\text { discussion }\end{array}$ & $\begin{array}{l}\text { each expert can } \\
\text { have his/her own } \\
\text { notebook for } \\
\text { documenting } \\
\text { discussion }\end{array}$ & $\begin{array}{l}\text { each expert can } \\
\text { have his/her own } \\
\text { notebook for } \\
\text { documenting } \\
\text { discussion }\end{array}$ & $\begin{array}{c}\text { Documentation } \\
\text { can be down with } \\
\text { software (MT-PR) } \\
\text { and each experts }\end{array}$ \\
\hline Shared space & $\begin{array}{l}\text { Table used as } \\
\text { shared space for } \\
\text { sharing } \\
\text { documents }\end{array}$ & $\begin{array}{c}\text { Whiteboard for } \\
\text { sharing ideas }\end{array}$ & Desktop & Projected wall & $\begin{array}{l}\text { Shared space is } \\
\text { defined with MT- } \\
\text { PR in the center of } \\
\text { multi-touch table }\end{array}$ \\
\hline Private space & $\begin{array}{l}\text { each expert can } \\
\text { have his/her } \\
\text { own printed } \\
\text { documents and } \\
\text { notebook as } \\
\text { private space }\end{array}$ & $\begin{array}{l}\text { each expert } \\
\text { can have } \\
\text { his/her own } \\
\text { notebook as } \\
\text { private space }\end{array}$ & $\begin{array}{c}\text { each expert can } \\
\text { have his/her own } \\
\text { notebook as } \\
\text { private space }\end{array}$ & $\begin{array}{c}\text { each expert can } \\
\text { have his/her own } \\
\text { notebook as } \\
\text { private space }\end{array}$ & $\begin{array}{l}\text { Each expert has } \\
\text { his/her own } \\
\text { private space that } \\
\text { is defined with } \\
\text { MT-PR }\end{array}$ \\
\hline
\end{tabular}


Table 1. (Continued)

\begin{tabular}{|c|c|c|c|c|c|}
\hline $\begin{array}{l}\text { Users accessibility to } \\
\text { shared space and } \\
\text { shared documents }\end{array}$ & $\begin{array}{l}\text { Accessible for } \\
\text { all experts }\end{array}$ & $\begin{array}{c}\text { Just the } \\
\text { member who } \\
\text { is writing the } \\
\text { ideas on the } \\
\text { board }\end{array}$ & $\begin{array}{c}\text { Just the member } \\
\text { who manipulate } \\
\text { mouse and } \\
\text { keyboard }\end{array}$ & $\begin{array}{c}\text { Just the member } \\
\text { who is } \\
\text { presenting }\end{array}$ & $\begin{array}{c}\text { Accessible for all } \\
\text { experts }\end{array}$ \\
\hline $\begin{array}{c}\text { Manipulating } \\
\text { documents / level of } \\
\text { manipulation }\end{array}$ & $\begin{array}{l}\text { Possible for all } \\
\text { experts/sharing } \\
\text { document with } \\
\text { other by putting } \\
\text { it in center of } \\
\text { table, each } \\
\text { person can put } \\
\text { annotation to the } \\
\text { documents }\end{array}$ & $\begin{array}{c}\text { Just the } \\
\text { member who } \\
\text { is writing the } \\
\text { ideas on the } \\
\text { board }\end{array}$ & $\begin{array}{c}\text { Just the member } \\
\text { who manipulate } \\
\text { mouse and } \\
\text { keyboard }\end{array}$ & $\begin{array}{c}\text { Just the member } \\
\text { who is } \\
\text { presenting }\end{array}$ & $\begin{array}{c}\text { Possible for all } \\
\text { experts / sharing } \\
\text { documents can be } \\
\text { down by changing } \\
\text { the position of } \\
\text { documents from } \\
\text { private space to } \\
\text { shared space/ each } \\
\text { person can put } \\
\text { annotation to the } \\
\text { documents }\end{array}$ \\
\hline $\begin{array}{l}\text { Ability to create link } \\
\text { between } \\
\text { objects(physical or } \\
\text { digital } \\
\text { documents/physical } \\
\text { or digital mockup) }\end{array}$ & $\begin{array}{c}\text { Hardly (staples, } \\
\text { paper clips...) }\end{array}$ & Is not possible & $\begin{array}{l}\text { Possible to create } \\
\text { link between } \\
\text { digital documents, } \\
\text { Just by who is } \\
\text { manipulating } \\
\text { mouse and } \\
\text { keyboard }\end{array}$ & Is not possible & $\begin{array}{l}\text { Possible to create } \\
\text { link between } \\
\text { digital documents } \\
\text { (2D and 3D) by } \\
\text { each expert }\end{array}$ \\
\hline
\end{tabular}

During the project review, each expert comes with folders containing the output of their previous activities. The goal is to exchange information between each expertise fields. At the end of the project review, each player has in mind the areas of work on which he will have to work. He leaves with a text document summarizing the decisions made during the project review, the milestones, and the actions to be held [14]. Following this review, each player returns to asynchronous working mode and process on specific areas of his expertise.

\section{$5 \quad$ Visual Collaborative and Interactive Tools to Support Project Review Phases in Product Development Process}

It seems that new technologies could be a good added value for project review. The organization 3 and 4 in Table 1 uses electronic documents and are well known attempts to reorganize meetings. But in most cases it is not fully satisfactory because a single user control the computer. The meeting is then mastered by one expert with potential side effects. We decided to develop a new solution dedicated to design 
project review on a multi-touch table (as supporting hardware). It provides both a shared display area for co-located people and a natural way of interaction over the displayed object. MT-PR (Multi Touch for Project Review) is an application under development to support the specificities mentioned above. Here we will demonstrate its functionality for project review during product development process (even if other type of project review could be concerned).

In Figure 4 the core meta-model governing MT-PR is provided, while Figure 6 is a prototype of specification for the user interface. Hereafter we explain both in detail.

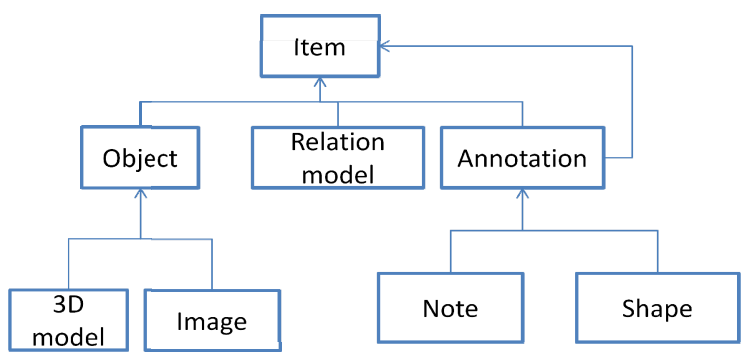

Fig. 4. Meta model dedicated to MT-PR for documentation aspect

MT-PR Hardware: Among the various facilities belonging to the Natural User Interface family, we chose the DiamondTouch table as supporting hardware. DiamondTouch is a multi-user touch technology for tabletop front-projected displays. Like other multi touch surfaces, it has the ability to recognize the presence of two or more points of contact with the surface but in addition it distinguishes who is touching where. It enables up to four different people to use the same surface simultaneously without interfering with each other [15]. Hence we can capture automatically who is doing what and this can be reported lately within the decision rationale. This hardware is appropriate for collaborative work when people are colocated. It provides interactive shared space with natural way of interaction.

User: the user is an expert who participates in project review meeting. He shares his documents with other experts and participates in discussion by transferring the interesting document for discussion, from private space to shared space. 


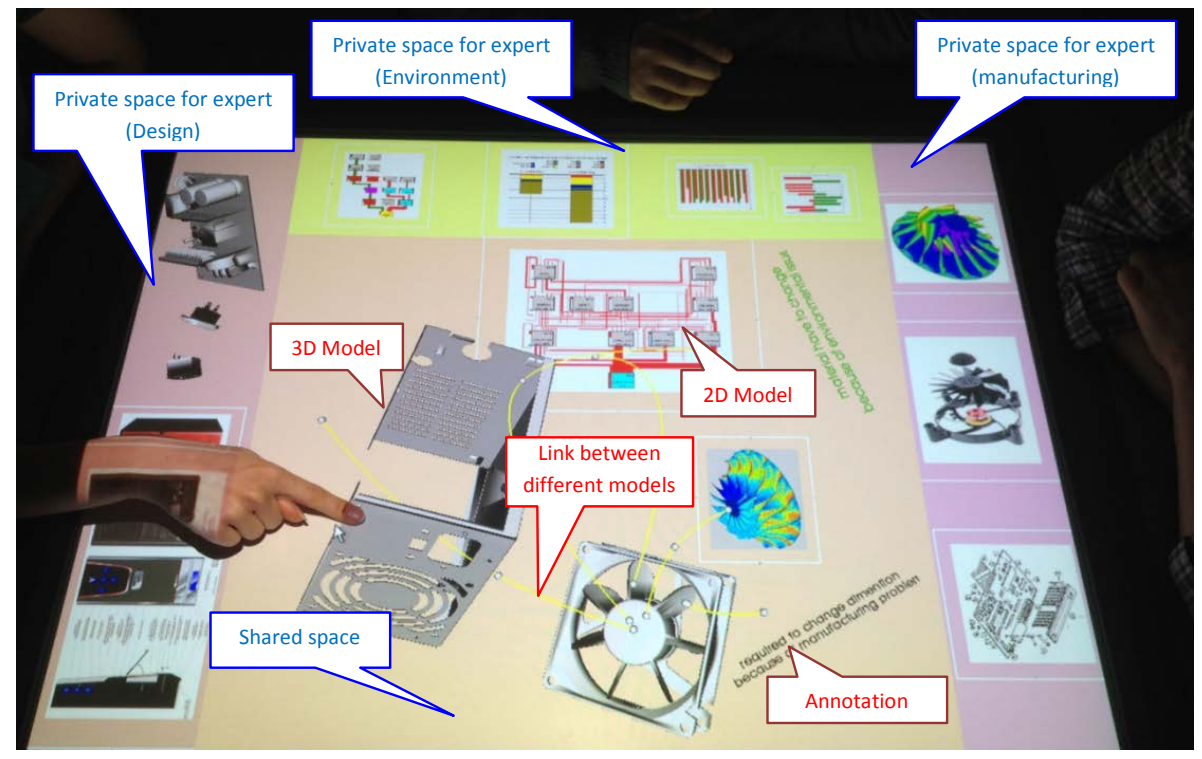

Fig. 5. An interactive discussion supported by MT-PR

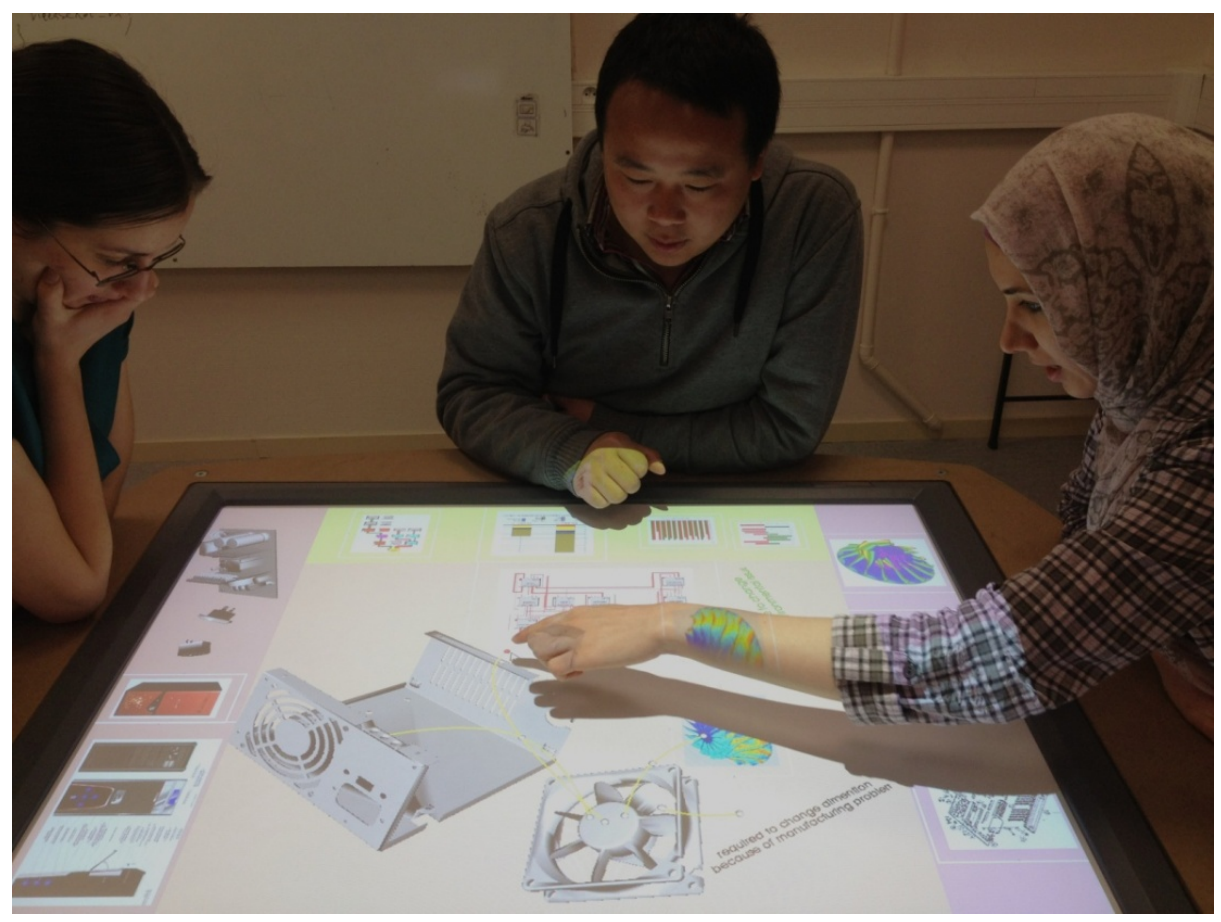

Fig. 6. Scenario of meeting between 3 expert for review of designing the computer housing project (environmental, manufacturing and design) and using MT-PR 
User Interface Design: This interface (Figure 5) may be described with the following properties:

- Shared space: center of the multi-touch table that is accessible for all experts to present and share any document,

- Private space: the part of multi touch that is accessible just for one expert to manipulate, to add documents related to his/her works.

- Main menu: to add new document, object to his/her private space.

- User Interaction: Multi touch table can provide a natural way of interaction with displayed objects.

- User interacts with $2 D$ or $3 D$ objects: to rotate, to translate, zoom in /zoom out, User interaction with $2 \mathrm{D}$ image is like $3 \mathrm{D}$ object but all is done in 2 axis instead of 3 axis.

- Documents are presented and shared as paper documents on a conventional table.

- A specific operator must help to define a selection of a subpart of this document.

- To add an annotation to a subpart of a document,

- To link two subparts of documents creating relationships between expert models.

Element of Meta model dedicated to MT-PR for documentation aspect: We propose a very simple model (Fig. 4) with a few elements which enable to trace the major links and annotations which are formulated during the cooperation phase. Indeed this model may be viewed as a new product model since it handles the connection between several views. Its simplicity is expected to ensure more intuitive actions in the previous graphic user interface.

- Object: Objects refer to the documents that expert display and share through multi touch table. These documents can be 3D model, 2D model (image/ pdf file). The object may have specific mechanisms to be split into sub objects for a fine description of relations between objects

- Relation: Relation is a connection between two objects. Connecting relevant documents and data will make sense in understanding the issues 'causes.

- Annotation: Annotation can be a text, an arrow with text, a symbols, a note, it can be public or private, it has author, and it can be anchored to the object thanks to a relation or anchored to another annotation. This may concern the object as a whole or only a part of it. Annotation on digital document through multi touch table can make sense like annotation in physical document, so it can be more natural and more convenient for user.

Project Review Report function: The previous model may be saved at any time. Thanks to the hardware capability we can automatically associate the identity (func- 
tion, expertise, or personal id) of item's authors and trace the timeline of the activity. This function is required to document the results of discussion, negotiation and decisions through the project review, to be sure that each expert can efficiently integrate the result in his work after this synchronous phase to continue in asynchronous mode. If experts can remember the ideas they come up with, they will be able to get a clue on the rest of their mental processing and remember the situation that lead to the emergence of this idea.

Documentation in MT-PR is consisting of: the documents that experts share and the annotation that are anchored to the documents (snapshot may also be embedded). This function provides a first way to automatically report the content of a cooperation meeting.

\section{Conclusion}

This paper specifies a tool to assist co-located synchronous collaboration during project reviews. These specifications derive from the analysis of the current practices usual lacks. By using this tool in project review, we expect the following results:

- A better support for collaboration and communication to ease exchange of information between different disciplines. Indeed the proposed system will mainly trace the links established between expert's models by allowing them to connect their own information. Hence, it will help to build a network of information for the sake of negotiation rationale.

- A facilitated process of conflicts detection by providing assistance tool for better understanding other expert's models with relationships between different models as previously mentioned.

- Better reporting of cooperation activities. This report ensures that experts can efficiently use the output of the project review. The ideal view could be to report automatically the decision of a cooperation step but also their rationale.

The specifications of the proposed tool where lead by the interest of getting a tool as intuitive as possible for most users to ease its deployment. A meta-model for structuring the report has been presented with the intention to integrate it within a PLM framework. It is thus based on an interaction metaphor which is really close to the usual meeting experience.

The next step in this research will be to experiment its usage in conventional situations and to measure its efficiency. Experimentations will compare the four common configurations of Table 1 with our proposed framework.

Focus is put on providing an interactive user friendly interface. The ability to present all the necessary data and information in the most seamless way might allows having an effective project review. The authors are convinced that the adoption of such "simple" tools could be a major step towards a better interoperability between experts involved when managing a product life providing complementary effects to the usual automated solutions. 


\section{References}

1. Davila, T.: An empirical study on the drivers of management control systems' design in new product development. Accounting, Organizations and Society 25, 383-409 (2000)

2. Damgrave, R.G.J., Lutters, D.: Multi-user Collaborative Design Tools for Use in Product Development. Global Product Development. Springer, Heidelberg (2011), doi:10.1007/978-3-642-15973-2_22

3. Betaieb, S., Noël, F.: A generic architecture to synchronies design models issued from heterogeneous business tools: towards more interoperability between design expertises. Engineering with Computers 24(1), 27-41 (2007)

4. Edwards, W.K.: Flexible conflict detection and management in collaborative applications. In: Proc. Symposium on User Interface Software and Techology (UIST 1997), Alberta, Canada, pp. 139-148 (1997)

5. Matta, N.: Conflict Management in Concurrent Engineering: Modeling Guides. In: Proceedings of ECAI 1996, 12th European Conference on Artificial Intelligence (1996)

6. Jung, H., Tambe, M., Kulkami, S.: Argumentation as distributed constraint satisfaction: applications and results. In: Proc. Fifth International Conference on Autonomous Agents, Montreal, Quebec, Canada, pp. 324-331 (2001)

7. Barber, K.S., Liu, T.H., Ramaswamy, S.: Conflict detection during plan integration for multi-agent systems. IEEE Trans. on System, Man, and Cybernetics- Part B: Cybernetics 31(4), 616-628 (2001)

8. Liu, Q., Cui, X., Hu, X.: Conflict Resolution within Multi-Agent System in Collaborative Design. In: International Conference on Computer Science and Software Engineering, IEEE (2008), doi:10.1109/CSSE.2008.679

9. Edwards, W.K.: Policies and roles in collaborative applications. In: Proc. ACM 1996 Conference on Computer Supported Cooperative Work (CSCW 1996), Cambridge, USA, pp. 11-20 (1996)

10. Guzdial, M., Rick, J., Kerimbaev, B.: Recognizing and supporting roles in CSCW. In: Proc. (CSCW 2000), Philadelphia, Pennsylvania, United States, pp. 261-268 (2000)

11. Zhu, H.: A Role-Based Conflict Resolution Method for a Collaborative System. In: IEEE International Conference on Systems, Man and Cybernetics, vol. 5, pp. 4135-4140 (2003)

12. Chapa, E.: Outils et structure pour la coopération formelle et informelle dans un contexte de conception holonique, Thèse doctorat, Institut National Polytechnique de Grenoble (1997)

13. Rogers, Y., Lindley, S.: Collaborating around vertical and horizontal large interactive displays: which way is best? Interacting with Computers 16(6), 1133-1152 (2004)

14. Prudhomme, G., Marin, R.P., Masclet, C.: An annotation tool to ease interactions and design decisions making report in project review context. In: Dans P. K. Y., Butdee, S., Sapsaman, T. (eds.) Proceedings of the 10th Global Congress on Manufacturing and Management. Bangkok, Thaillande, pp. 62-71 (2010), http://hal.archivesouvertes.fr/hal-00540180

15. Dietz, P., Leigh, D.: Diamond Touch: A Multi-User Touch Technology. In: Proc. of UIST 2001, pp. 219-226. ACM, NY (2001) 